\title{
Suicide risk in systemic lupus erythematosus: A narrative review
}

\author{
Solange Barros, Jozélio Freire de Carvalho* \\ Institute for Health Sciences from Federal University of Bahia, Brazil
}

Received: December 27, 2020

Accepted: September 7, 2021

Online Published: September 26, 2021

DOI: $10.5430 /$ dcc.v8n3p9

URL: https://doi.org/10.5430/dcc.v8n3p9

\begin{abstract}
Introduction: Despite the medical and scientific advances, the disease's restrictions and the perception of personal and social losses related to its course reinforce fear and generate intense suffering in lupus patients. Psychiatric comorbidities, especially major depressive episodes, are highly prevalent during systemic lupus erythematosus. Among them, suicide is a behavior that is much more common than we believe.

Objective: To perform a narrative review on suicidal behavior associated with systemic erythematosus lupus (SLE).

Results: Studies have shown an increased risk of suicide among patients with chronic diseases and psychiatric disorders, especially depression. However, suicide cannot be attributed only to a higher prevalence of depression and other mental illnesses. Therefore, it is necessary to learn more about the suicide risk factors present in patients with lupus to work on secondary prevention and avoid the premature loss of lives and the additional suffering of families and surrounding communities. The coordination between the studies on suicidal behavior and its intricate network of individual and sociocultural factors and the studies on this multisystem autoimmune disease with a broad manifestation spectrum, lupus, creates new and essential field research.

Conclusions: Non-psychiatrist office-based physicians, health clinics, or wards dedicated to the treatment of SLE should recognize and handle the suicide risk factors on their patients to reduce the suffering caused by this disease.
\end{abstract}

Key Words: Lupus erythematosus, Systemic, Nervous system diseases, Mental disorders, Suicidal ideation, Suicide

\section{INTRODUCTION}

Semantically, suicide is defined as a self-inflicted death performed by an individual conscious of its consequences, and its frequency is usually under-reported due to cultural influences. It is a complex behavior process that comprises suicidal ideation, planning, attempts, and fatal acts..$^{[1,2]}$

Although human beings are, by nature, attached to their survival instinct and are afraid of death, some of them consider death an alternative to relieve or solve their problems, in contrast to the perspective of a painful life, which can lead to suicidal behavior. ${ }^{[3,4]}$ Among chronically ill patients (e.g., painful syndromes associated with cancer and HIV), mortality is estimated to be four times greater than in the general population and even higher when associated with a psychiatric disorder, especially depression. ${ }^{[1,5-7]}$

Systemic Lupus Erythematosus (SLE) is a chronic autoimmune disease with a broad clinical manifestation spectrum. It includes neuropsychiatric syndromes that vary from moderate emotional disorders to more significant depression episodes and severe psychosis. ${ }^{[10,12-14]}$ Brazil.

*Correspondence: Jozélio Freire de Carvalho; Email: jotafc@gmail.com; Address: Institute for Health Sciences from Federal University of Bahia, 
Despite the medical and scientific advances, the restrictions imposed and the perception of losses related to this disease's course reinforce fear and generate intense physical and psychological suffering in lupus patients. In several cohort studies of SLE, suicide is a self-destructive event more frequent than usually believed, emphasizing that suicidal ideation and planning in lupus patients increased in the presence of psychiatric comorbidities, reaching the risk of up to five times higher than the average risk in the population. ${ }^{[1,11]}$

Most studies of patients with lupus estimate the frequency of suicide attempts between $8.3 \%$ and $12.4 \% .{ }^{[9-14]}$ Differently, a single study reported a frequency of up to $34.4 \%$ of ongoing suicidal ideation in a group of Chinese patients with lupus, in which case the authors associate it with financial problems, family breakdown, beliefs, and psychological conditions (before the disease) associated to the negative manner of facing the crisis. ${ }^{[15]}$

The objective of this article is to perform a narrative review of suicide and SLE.

\section{RISK AND PROTECTIVE FACTORS}

The literature demonstrates that unemployed people, especially when they are the family's primary provider, and those who live under the government's financial aid, are more prone to commit suicide. ${ }^{[4,14,16,17]}$ Whereas, the social cohesion manifested by belonging to stable social groups, like religious and work institutions, therapeutic support groups, strong family bonds, as well as the support from caregivers and friends is known as the leading environmental protective factor against suicide tendencies. ${ }^{[12-15]}$

Therefore, people with a low level of education, poor economic situation, social isolation stigmas, and belonging to family groups are dismantled by divorce, recently widowed, abandoned, or mistreated, who cease being engaged in any social activity community to exhibit the risk of developing suicidal behavior. ${ }^{[1,5,16,17]}$

There are controversial data about the genetic disposition to self-destructive behavior since it is difficult to exclude from the analysis of severe psychological trauma associated with suicide history in the family. ${ }^{[5-7]}$

Regarding sex, males usually have higher mortality related to suicide, while more attempts are associated with females. Infertility, sexual dysfunctions, and gender dysphoria can also be inciting conflicts for suicidal ideation. Sex also affects the choice of methods. At the same time, men usually prefer firearms, hanging, or jumping from high places; women prefer to use gas asphyxiation, drug intoxication, and insecticide, and rat poison in rural environments. ${ }^{[6,7,14]}$
The age range of greater risks is, universally, elderly and young adults. Among the elderly, the occurrence of chronic and progressive diseases and neuropsychiatric comorbidities with cognitive changes are considered related factors. Among young adults, the factors are immaturity, impulsivity, aggressiveness, and the use of psychoactive drugs..$^{[1,5,18,19]}$

The theory that prevails is that almost all the suicide cases are related to a previous psychiatric imbalance, capable of distorting reality along with feelings of despair, abandonment, and desperation, which ends in a suicide attempt. ${ }^{[11,16]}$

On the one hand, depression, alcohol, and substance abuse are frequent in people who commit suicide; on the other hand, concerning mental illnesses, people with bipolar disorders, schizophrenia, and antisocial and borderline personality disorders are more prone to commit suicide. The risk increases directly according to the negative symptoms and the degree of functional repercussion, not due to the productive symptoms' exuberance. The most impacted are not the mentally ill, but the ones with well-functioning minds before the disease, with critical judgment to notice the impact of the psychiatric illness and are pessimist about the treatment outcome. ${ }^{[5,7,12,13]}$

Some researchers suggest low serotonin concentration in the central nervous system as a suicide marker, but it is more likely to signal an underlying depression. However, digressing for a moment, if suicide can be considered the devastating consequence of depression, it is also possible that the torturing suicidal ideation can be the cause, or worsening factors, of the same depression. ${ }^{[9,10]}$

Prescribing lithium for bipolar disorders and clozapine for schizophrenia are the chosen therapeutic schemes to reduce the risk of suicide since they act controlling impulsivity and aggressiveness. ${ }^{[20-22]}$ However, many continued use of psychotropic drugs have been reported as inducing suicidal behavior, like benzodiazepines, narcotic analgesics, and anticonvulsants, in older adults, and serotonin receptor blockers, appetite suppressants, and hallucinogenic drugs in teenagers. ${ }^{[18,23,24]}$

There are warnings that some non-psychoactive drugs can have a side effect of suicidal ideation, like efavirenz, an antiretroviral used in HIV treatment, and isotretinoin, used in skincare treatments in teenagers and young adults with acne. ${ }^{[25,26]}$

Concerning corticosteroids, used in high dosage for treating neuropsychiatric conditions in lupus patients, although they can be related to psychotic breaks, there is some controversy in the literature whether it is indifferent or can increase the risk of suicide, it seems that the worst problem is due to 
the withdraw process, when the drug can reach levels below the optimum for clinical management, causing suicidal ideation. ${ }^{[2,27-29]}$

Regarding taking a suicidal drug overdose, a large nationwide population-based case-control study was performed in Taiwan. The authors found in 20,961 cases of SLE in comparison to $1,000,000$ controls a higher risk of SDO in lupus that was 291:100,000 cases compared to 160:100,000 in rules and SDO was associated, in a multivariate analysis, with depression, insomnia, and low income. ${ }^{[30]}$

\section{SUICIDAL RISK FACTORS ASSOCIATED WITH SLE}

Concerning suicidal risk factors in lupus patients, there is an overlapping among the risks known to be present in the general population and nosology-specific. The high risk for survivors of previous suicide attempts (more recent, more dangerous), as well as those in a vulnerable social situation and having neuropsychiatric symptoms, especially cases of major, chronic, recurrent, or undertreated depression, psychosis, or schizophrenia, are also valid for patients with lupus. Chronic, recurrent, acute, unknown, or undertreated psychiatric comorbidities increase the risk of suicidal behavior in this group of patients and should be suspected when there are symptoms like sleep or appetite disorder, fatigue, alcohol, and drug abuse, as well as resistance, irregular continuity, or abandoning of the conventional treatment. The difficulty in accessing mental health specialized treatment can also be considered as a risk fator. ${ }^{[2,6,7,10]}$

There is no consistent evidence in the literature of autoimmune or non-specific inflammatory mechanisms associated with suicide risk in lupus patients, maybe due to the studies' methodologic limitations at that time. Not even the presence of $\mathrm{P}$ antigen was recognized as a risk predictor. New study models that include suicide risk as a variable for cohort segments of lupus patients are necessary to understand this matter better. ${ }^{[2,10]}$

Genetic factors are also linked to suicide in SLE. The role of glutamate receptor gene polymorphisms in suicidal behavior was evaluated in 130 SLE patients, and a significant association was found between suicidal ideation and the NR2A rs2072450 AC genotype polymorphism. ${ }^{[31]}$

Suicidal thoughts were present in $25 \%$ of patients with NPSLE, irrespective of sex, age, education, work status, disease duration, and steroid treatment in a study with 53 lupus subjects. Moreover, suicidal ideation was connected with elevated levels of depression, anxiety, and irritability. ${ }^{[32]}$

Periods of uncertainty regarding prognosis are also associ- ated with a greater risk of suicide, which in lupus patients corresponds to the onset of the disease and the phases of organ failure aggravation or treatment resistance, especially in neuropsychiatric cases where cognitive worsening is evidenced. The progression time is not as relevant regarding the control stage and, although there is no well-established connection between the disease activity indexes and suicide risk, injuries in some target organs are likely more prone to induce suicide in others. Cardiopulmonary complications with pleuritic pain, fatigue, and a dramatic reduction in a functional capacity related to daily activities are heavily associated with suicide risks. ${ }^{[8-14]}$

In patients with SLE, the primary suicide method is abusing the medication used to treat their comorbidities, like painkillers and psychoactive drugs. ${ }^{[2-8]}$ That is why, it is critical to provide information to patients and caregivers about the drug treatment risks, emphasizing the importance of following the prescribed dosage and the correct guidance regarding disposing of the leftover pills. Health professionals should avoid providing large amounts of medicine to vulnerable patients and warn caregivers to restrict them from accessing treatment. ${ }^{[22,23,30]}$

The person classified as high risk commits suicide but evaluating this risk and handling these patients can reduce new cases. In contrast, further studies are still necessary to better specify the drivers of this process. ${ }^{[1-13]}$

\section{Assessment tools}

If predicting when someone will commit suicide is almost impossible, it is possible to learn about and classify the risk factors that can play a role in suicide and use it in decisionmaking. Until recently, only epidemiological and statistical surveys were employed as tools for suicide tendencies. Today, nonetheless, flourish attempts to outline the multiple information involved in this phenomenon in the form of standardized protocols and questionnaires to qualify the gravity of suicidal ideation and behavior. In general, these instruments show high sensitivity and low specificity and help track risk groups within a population, but they do not prove good predictive values. Furthermore, they demand psychometric training for those who administer them, and its format is impractical for daily usage in a clinic. ${ }^{[34-37]}$

To name only a few of the most well-known screening tools, we can mention the Beck Scale Adapted for Suicide Ideation (BSS), ${ }^{[38]}$ the Suicide Behaviors QuestionnaireRevised (SBQ), ${ }^{[39]}$ Sheehan Suicidality Tracking Scale (SSTS $),{ }^{[40]}$ and the Columbia Suicide Severity Rating Scale (C-SSRS). ${ }^{[41]}$ The last one, especially in its reduced form, not requiring the examiner to have mental health training, has 
been used as a standard in several international government agencies and its computerized version. ${ }^{[42]}$

\section{Clinical management}

Each lupus patient visit is necessary to look for signs of suicidal behavior, even if concealed by somatic complaints, using therapeutic listening, spoken approach, and risk factors evaluation. For this purpose, an inquiry with two blocks of three gradual questions should be added to the anamnesis: the first one for universal screening; and the second one for the selective approach of patients with suspected risk based on the initial responses. ${ }^{[6,7,41]}$

Although it is impossible to predict who will commit suicide, the health professional, even if not specialized in mental health, can evaluate the level of suicide risk and decide de proper handling for each case, rating the risk as low, medium, or high.

Low-risk cases would be the ones where there is suicidal ideation but no planning; medium risk cases would be the ones where there are the suicidal ideation and planning, but the person does not intend to execute them immediately; highrisk cases are those where the patient has plans, opportunity and defined means, and indicates that the action is imminent, therefore, constitutes a medical-psychiatric emergency. ${ }^{[2,41]}$

The recommended handling of patients considered prone to suicidal behavior goes from the basic, recommended for lowrisk cases, which includes therapeutic listening, acceptance, and information about suicide protecting factors, binding to emotional support instruments like suicide prevention lifeline or support groups that can reduce isolation and discuss the suicidal thoughts in a way to offer options and reduce the tension. The doctor still must diagnose and treat associated psychiatric disorders. If the symptoms persist, the doctor ought to arrange specialized mental health evaluation, always with the request of counter-reference. ${ }^{[6,7,43,44]}$

For the medium-risk cases, patients must be sent as soon as possible for a psychiatric evaluation. Family members and friends must be contacted after the patient's consent. It is necessary to invest in protective factors, block the patient's access to the means (firearms, knives, poison, and medicine), and guide the prevention to associated risks (not to ingest alcoholic beverages and other drugs, avoid high places, and driving). The high-risk cases must be treated as psychiatric emergencies. It is essential to increase attention to space and to reduce risks, establishing from the first moment a safe room for medical care. ${ }^{[7,42,43]}$

The patient in this stage cannot be left alone anytime, and transportation to a psychiatric emergency room is only allowed by ambulance, never by individual means or nonprofessionals. In turn, the emergency rooms will reduce the immediate risk, recommend hospitalization during a crisis and mental health monitoring. It is vital to actively address the suicide attempt survivors, their family members and friends, and their community. The quaternary prevention is essential to avoid new attempts. ${ }^{[11,13]}$

Technology solutions in detecting and preventing cases can be helpful to instruments. For example, data systems that can cross-reference personal health records; intelligent machines that can analyze the answers from the evaluation instruments using voice recognition patterns; analysis tools incorporated into the patient's electronic records capable of treating data, evaluate suicide data, generate warnings, and suggest actions to be taken by the doctors; as well as multiplying interactive solutions like camera surveillance, crisis sensors, and alert systems; daily monitoring by electronic messages and applications for smartphones. These solutions can be useful, but they can still not offer comprehensive results that can replicate the human support between people at risk and their support agents. ${ }^{[44-47]}$

\section{Conclusion}

Suicidal behavior is more frequent in SLE than we recognize. Developing new strategies for assessing the risk factors and including handling protocols for the medical practice, even for non-psychiatrists, is essential to reduce its persistence and evolution. Special attention must be given to high-risk patients, not only those who reveal imagination and plans to commit suicide but also those who survived recent attempts, whose risk of new endeavors, despite an appearing post-crisis improvement, can be even greater.

The coordination between the studies about suicidal behavior and its intricate network of individual and sociocultural factors with the studies on this multisystem autoimmune disease with a broad manifestation spectrum, which is lupus, creates a new and vital field of research, where new studies can clarify the clinical interrelationships and increase the predictive value of specific evaluation tools.

\section{CONFliCtS OF INTEREST Disclosure}

The authors declare they have no conflicts of interest. 


\section{REFERENCES}

[1] Bertolote JM. The suicide and its prevention. São Paulo: UNIFESP; 2012.

[2] Karassa FB, Magliano M, Isenberg DA. Suicide attempts in patients with systemic lupus erythematosus. Ann Rheum Dis. 2003; 62(1): 5860. PMid:12480670. https://doi.org/10.1136/ard.62.1.58

[3] Durkheim E. The suicide. São Paulo: Martin Claret; 2005. https: //doi.org/10.4324/9780203994320

[4] Frankl VE. The will to meaning: foundations and applications of logotherapy. São Paulo: Paulus; 2011.

[5] Botega NJ, et al. Suicidal behavior in the community: prevalence and factors associated with suicidal ideation. Rev Bras Psiquiatr. 2005; 27(1): 45-53. PMid:15867983. https://doi.org/10.1590/S1 516-44462005000100011

[6] World Health Organization. Preventing suicide: a global imperative. Geneva: WHO Library; 2014.

[7] BRazilian Association of Psychiatry and Federal Council of Medicine. Suicide: reporting to prevent. Brasília: FCM/BAP; 2014. 53 p.

[8] Futrell N, Schultz LR, Millikan C. Central nervous system disease in patients with systemic lupus erythematosus. Neurology. 1992; 42(9): 1649-1657. PMid:1513450. https ://doi.org/10.1212/WNL . 42 .9 .1649

[9] Jarpa E, et al. Common mental disordersand psychological distress in systemic lupus erythematosus are not associated with disease activity. Lupus. 2011; 20(1): 58-66. PMid:21078764. https : //doi.org/10.1177/0961203310381773

[10] Asano NMJ, et al. Comorbidades psiquiátricas em pacientes com lúpus eritematoso sistêmico: uma revisão sistemática dos últimos 10 anos. Rev Bras Reumatol. 2013; 53(5): 431-437. PMid:24316900. https ://doi.org/10.1590/S0482-50042013000500010

[11] Harris EC, Barraclough BM. Suicide as an outcome for medical disorders. Medicine. 1994; 73(6): 281-296. PMid:7984079. https://doi.org/10.1097/00005792-199411000-00001

[12] Ishikura R, Morimoto N, Tanaka K. Factors associated with anxiety, depression and suicide ideation in female outpatients with SLE in Japan. Clin Rheumatol. 2001; 20(6): 394-400. PMid:11771521. https ://doi.org/10.1007/s100670170002

[13] Zakeri Z, et al. Prevalence of depression and depressive symptoms in patients with systemic lupus erythematosus: Iranian experience. Rheumatol Int. 2012; 32: 1179-1187. PMid:21253731. https ://doi.org/10.1007/s00296-010-1791-9

[14] Mok CC, et al. Suicidal ideation in patients with systemic lupus erythematosus: incidence and risk factors. Rheumatology. 2014; 53(4): 714-721. PMid:24361695. https ://doi.org/10.1093/rheuma tology/ket 404

[15] Xie LF, et al. Prevalence and correlates of suicidal ideation in SLE inpatients: chinese experience. Rheumatol Int. 2012; 32(9): 27072714. PMid:21792644. https://doi.org/10.1007/s00296-0 11-2043-3

[16] Bertolote JM, et al. Suicide attempts, plans, and ideation in culturally diverse sites: the WHO SUPRE-MISS community survey. Psychol Med. 2005; 35(10): 1457-1465. PMid:16164769. https : //doi.org/10.1017/S0033291705005404

[17] Frasquilho D, et al. Mental health outcomes in times of economic recession: a systematic literature review. BMC Public Health. 2016; 16: 115. PMid:26847554. https://doi.org/10.1186/s12889 -016-2720-y

[18] Moreira LCO, Bastos PRHO. Prevalence and factors associated with suicidal ideation in adolescence: literature review. School Educat Psychol. 2015; 19(3): 445-453.

[19] Vasconcelos-raposo J, et al. Levels of suicidal ideation in young adults. Psychology Studies. 2016; 33(2): 345-354.
[20] Cipriani A, et al. Lithium in the prevention of suicide in mood disorders: updated systematic review and meta-analysis. BMJ. 2013; 27(346): f3646. PMid:23814104. https ://doi.org/10.1136/bm j.f 3646

[21] Jagodic HK, Agius M, Pregelj P. Psychopharmacotherapy prescription and suicidal behaviour. Psychiatr Danub. 2013; 25(2): S324-8.

[22] Fawcett JA, et al. Definition and management of suicidality in psychiatric patients. J Clin Psychiatry. 2009; 70(10): e38. PMid:19906337. https ://doi.org/10.4088/JCP.8145tx1c

[23] Lavigne JE, et al. Utilization of prescription drugs with warnings of suicidal thoughts and behaviours in the USA and the US Department of Veterans Affairs, 2009. J. Pharm. Health Serv. Res. 2012; 3 : 157-163. https://doi.org/10.1111/j.1759-8893.2012.000 $93 . \mathrm{x}$

[24] Pereira A, et al. Suicidality associated with antiepileptic drugs: implications for the treatment of neuropathic pain and fibromyalgia. Pain. 2013; 154(3): 345-349. PMid:23375513. https ://doi.org/10.1 $016 / j \cdot$ pain. 2012.12.024

[25] Apostolova N, et al. Efavirenz and the CNS: what we already know and questions that need to be answered. J. Antimicrob. Chemother. 2015; 70(10): 2693-2708. PMid:26203180. https ://doi .org/10 $.1093 / \mathrm{jac} / \mathrm{dkv} 183$

[26] Madeira N, et al. Isotretinoin, Depression and Suicide. Rev. Psiquiatr Clín. 2012; 39(2): 76-77. https ://doi .org/10.1590/S0101-6 0832012000200007

[27] Voaklander DC, et al. Medical illness, medication use, and suicide in seniors: a population-based case-control study. J. Epidemiol. Com. Health. 2008; 62(2): 138-146. PMid:18192602. https://doi.or g/10.1136/jech. 2006.055533

[28] Fardet L, Petersen I, Nazareth I. Suicidal behavior and severe neuropsychiatric disorders following glucocorticoid therapy in primary care. Am. J. Psych. 2012; 169(5): 491-497. PMid:22764363. https://doi.org/10.1176/appi.ajp.2011.11071009

[29] Fardet L, et al. Severe neuropsychiatric outcomes following discontinuation of long-term glucocorticoid therapy: a cohort study. J. Clin. Psychiatr. 2013; 74(4): e281-286. PMid:23656853. https : //doi.org/10.4088/JCP. 12m08034

[30] Tang KT, et al. Suicidal drug overdose in patients with systemic lupus erythematosus, a nationwide population-based case-control study. Lupus. 2016; 25(2): 199-203. PMid:26405026. https://doi.or $\mathrm{g} / 10.1177 / 0961203315608253$

[31] Buji RI, et al. Suicidal ideation in systemic lupus erythematosus: NR2A gene polymorphism, clinical and psychosocial factors. Lupus. 2017; 961203317742711. PMid:29161964. https ://doi .org/10 $.1177 / 0961203317742711$

[32] Hajduk A, et al. Prevalence and correlates of suicidal thoughts in patients with neuropsychiatric lupus. Lupus. 2016; 25(2): 185-92. PMid:26359173. https://doi.org/10.1177/09612033156031 36

[33] Sarchiapone M, et al. Controlling access to suicide means. Int. J. Environ. Res. Public. Health. 2011; 8(12): 4550-4562. PMid:22408588. https://doi.org/10.3390/ijerph8124550

[34] Goldstein RB, et al. The prediction of suicide. sensitivity, specificity, and predictive value of a multivariate model applied to suicide among 1906 patients with affective disorders. Arch. Gen. Psychiatr. 1991; 48(5): 418-422. PMid:2021294. https://doi.org/10.1001/ar chpsyc. 1991.01810290030004

[35] Paris J. Predicting and preventing suicide: do we know enough to do either? Harvard. Rev. Psychiatry. 2006; 14(5): 233-240. PMid:16990168. https ://doi.org/10.1080/10673220600968 662 
[36] Large MM, Ryan CJ. Suicide risk assessment: Myth and reality. Int. J. Clin. Pract. 2014; 68(6): 679-681. PMid:24837091. https://doi.org/10.1111/ijcp. 12378

[37] Haney EM, et al. Suicide risk factors, and risk assessment tools: a systematic review. Washington (DC): Department of Veterans Affairs; 2012.

[38] Beck AT, Kovacs M, Weissman A. Assessment of suicidal intention: the Scale for Suicide Ideation. J. Consult. Clin. Psycho. 1979; 47(2): 343-352. PMid:469082. https ://doi .org/10.1037/0022-006 $\mathrm{X} .47 .2 .343$

[39] Osman A, et al. The Suicidal Behaviors Questionnaire-Revised (SBQ$\mathrm{R})$ : validation with clinical and non-clinical samples. Assessment. 2001; 8: 443-454. PMid:11785588. https ://doi.org/10.1177/ 107319110100800409

[40] Sheehan DV, Giddens JM, SHEEHAN IS. Status update on the Sheehan-suicidality tracking scale (S-STS) 2014 Innov. Clin. Neurosci. 2014; 11(9-10): 93-140.

[41] Posner K, et al. The Columbia-suicide severity rating scale: initial validity and internal consistency findings from three multisite studies with adolescents and adults. Am. J. Psychiatry. 2011; 168(12): 1266-1277. PMid:22193671. https://doi.org/10.1176/appi .ajp. 2011.10111704

[42] Mundt JC, et al. Feasibility and validation of a computer-automated Columbia-Suicide severity rating scale using interactive voice re- sponse technology. J. Psychiatr. Res. 2010; 44(16): 1224-1228. PMid:20553851. https://doi.org/10.1016/j.jpsychires.2 010.04 .025

[43] Fleischmann A, et al. Effectiveness of brief intervention and contact for suicide attempters: a randomized controlled trial in five countries. Bull. World. Health. Organ. 2008; 86(9): 703-709. PMid:18797646. https://doi.org/10.2471/BLT.07.046995

[44] Haupt M, et al. Improvement of coping abilities in patients with systemic lupus erythematosus: a prospective study. Ann. Rheum. Dis 2005; 64: 1618-1623. PMid:15829575. https://doi.org/10.1 136/ard. 2004.029926

[45] Vahabzadeh A, Sahin N, Kalali A. Digital suicide prevention: can technology become a game-changer? Innov. Clin. Neurosci. 2016; 13(5-6): 16-20.

[46] Larsen ME, Nicholas J, Christensen HA. Systematic Assessment of Smartphone Tools for Suicide Prevention. PLoS One. 2016; 11(4): e0152285. PMid:27073900. https ://doi.org/10.1371/journa 1. pone. 0152285

[47] Audemard-Verger A, et al. Is it relevant to screen young women hospitalized in the psychiatric department for neuropsychiatric systemic lupus erythematosus (NPSLE)? A prospective study of 100 psychiatric inpatients. Medicine (Baltimore). 2016; 95(47): e5288. PMid:27893665. https ://doi.org/10.1097/MD.00000000000 05288 